\title{
Prospects for Realizing International Women's Rights Law Through Local Governance: the Case of Cities for CEDAW
}

\author{
Anne Sisson Runyan ${ }^{1} \cdot$ Rebecca Sanders $^{1}$ (D) \\ Accepted: 18 August 2021/ Published online: 4 September 2021 \\ (C) The Author(s), under exclusive licence to Springer Nature B.V. 2021
}

\begin{abstract}
How best to realize international human rights law in practice has proved a vexing problem. The challenge is compounded in the USA, which has not ratified several treaties including the Convention on the Elimination of All Forms of Discrimination against Women (CEDAW). The Cities for CEDAW movement addresses this deficit by encouraging cities to endorse and implement CEDAW norms. In doing so, it seeks to catalyze a local boomerang effect, whereby progressive political momentum at the local level generates internal pressure from below to improve gender equity outcomes across the country and eventually, at the national level. In this article, we trace the diffusion of Cities for CEDAW activism with attention to the case of Cincinnati and analyze its implications for advancing women's rights principles. We argue that while Cities for CEDAW has potential to enhance respect for women's rights in local jurisdictions, its impact on national policy remains limited.
\end{abstract}

Keywords International law · Women's rights · Cities for CEDAW · Feminism • Activism $\cdot$ Local government

"Make the Global Local" declares Cities for CEDAW (Convention on the Elimination of all Forms of Discrimination against Women), a dynamic feminist campaign to "protect the rights of women and girls by adopting the principles of CEDAW in cities and towns across the United States" (Cities for CEDAW 2017 , p. 1). Motivated by the USA's refusal to ratify CEDAW (1979) ${ }^{1}$ as the core international human rights treaty focused on women's rights, the absence of

1 The Holy See, Iran, Palau, Somalia, Sudan, and Tonga have also failed to ratify CEDAW.

Rebecca Sanders

rebecca.sanders@uc.edu

Anne Sisson Runyan

anne.runyan@uc.edu

1 Department of Political Science, University of Cincinnati, 1110 Crosley Tower, 301 Clifton Ct, Cincinnati, USA 
constitutional rights specifically protecting women, and the ongoing discrimination, abuse, and inequality experienced by many US women, Cities for CEDAW aims to improve women's rights policies and practices in local governance and leverage local support to press for broader change, including eventual national ratification of CEDAW. To achieve this in practical terms, CEDAW cities are encouraged to pursue a three-prong approach: "a gender analysis of city operations (e.g., workforce, programs, budget); an oversight body to monitor the implementation of a local CEDAW ordinance, (e.g., Commission on the Status of Women, Human Rights Commission, etc.); and funding to support the implementation of CEDAW principles" (Cities for CEDAW 2017). So far, nine American cities and counties have adopted ordinances that commit them to observance of CEDAW principles, while dozens more have passed resolutions or are developing plans to join the movement (Cities for CEDAW 2019). The Cities for CEDAW campaign thus provides a unique opportunity to analyze the dynamics of "glocal" activism that traverses global to local scales (Escobar 2001; Lindell 2009; Roudometof 2015) and examine its capacity to advance international human rights norms and practices.

Cities for CEDAW seeks to catalyze what we call a local boomerang effect, whereby progressive political momentum at the local level generates internal pressure from below to improve gender equity outcomes across the country and eventually, at the national level. While domestic human rights activists often reach up to the international community in the face of recalcitrant national governments, hoping international pressure to comply with human rights commitments will "boomerang" back home (Keck and Sikkink 1998), this option is generally unavailable to American feminists, both because the USA has not ratified CEDAW and because foreign actors lack leverage to sway US domestic policy. The American Cities for CEDAW movement also utilizes the dynamics of multiscalar influence, but reaches down to the local level, encouraging horizontal diffusion of CEDAW principles across local governments. Ideally, pressure from empowered Cities for CEDAW jurisdictions engaged in routinized compliance with the spirit or letter of CEDAW will then boomerang back to state and federal levels of government, improving prospects for national ratification. Cities for CEDAW does not postulate a definitive "tipping point" for achieving sustained influence, but aims to root itself in at least one hundred US jurisdictions (Womack 2015).

We argue that in some ways, the local boomerang model can be efficacious. As we later analyze via several case studies, Cities for CEDAW successfully fosters local government engagement with CEDAW principles, carving a pathway through which community activists can scrutinize and critique local policies and practices and pressure policymakers to enact recommendations. Because Cities for CEDAW provides a toolkit, including language, metrics, model legislation, and other sample templates that can be borrowed and deployed to evaluate and promote gender and other interrelated forms of equity, it is highly diffusible. Through these interactions, advocates can leverage the insights of contemporary feminists and grassroots community activists, who recognize women's rights are indivisible from racial minority, sexual minority, and non-normative gender 
rights as well as economic rights, in order to make CEDAW more responsive to the realities of intersectional oppression. By connecting gender equity to an international women's rights treaty, Cities for CEDAW moreover promotes the idea that women's rights are inherent human rights, not contingent policy options or negotiable preferences.

However, our own policy research experience as part of an effort to "make CEDAW local" suggests some significant limitations to recognizing and respecting women's international human rights conventions in the USA at local, state, and national levels. The opportunity structure created by Cities for CEDAW cannot necessarily overcome bureaucratic inertia or compel lasting change in the absence of political will in a country where basic women's rights remain contested. International human rights frames do not resonate particularly strongly in many jurisdictions. Local governments do not always have the resources to pursue sweeping initiatives. Perhaps, most importantly, despite gaining traction in dozens of municipalities, there are few indications that local progress has translated into coherent national gender equity policy, let alone imminent prospects for CEDAW ratification. On balance, we therefore conclude that Cities for CEDAW is a worthy enterprise, but that the local boomerang effect remains muted. Rather, the movement's primary success lies in more incremental reforms to local policy and practices.

In developing our analysis, we review the history and current status of women's rights protections in the USA. We then explore interplays between global and local human rights politics. We move to the literature on the Cities for CEDAW campaign as an example of the glocalization of women's rights, with attendant strengths and weaknesses associated with the local boomerang effect. We highlight the San Francisco case as the first city to adopt a Cities for CEDAW ordinance and the Cincinnati case, as a more recent one. As authors of a gender equity study of and for the City of Cincinnati authorized by a Cities for CEDAW ordinance, we are in a unique position to assess this case. ${ }^{2}$ We conclude by evaluating opportunities and obstacles for this form of city-centered advocacy.

Although it has much promise, we argue that the Cities for CEDAW model complements but cannot ultimately substitute for national treaty ratification. The realization of CEDAW principles in the USA requires consistent adoption across the country and the cooperation of the federal government. Looking abroad, the USA's capacity to advance women's rights internationally is hindered by its rejection of CEDAW. In these ways, Cities for CEDAW reveals both the potential and limits of making the global local.

\footnotetext{
2 Our direct involvement with the campaign positions us in the tradition of participatory action research, which suggests that "insiders have special advantages when it comes to doing research in their own sites and to investigating practices that hold their work and lives together in those sites" (Kemmis, McTaggart, and Nixon 2014: p. 5). Such research "conducted by participants is oriented to making improvements in practices and their settings by the participants themselves" (Kemmis, McTaggart, and Nixon 2014: p. 4).
} 


\section{Women's Rights Law in the USA}

Despite the USA's tremendous wealth and power, American women continue to suffer discrimination, abuse, and inequality. They are paid $82 \%$ of men's wages on average (American Association of University Women 2021), have the highest maternal mortality rates in the developed world (Martin and Montagne 2017), and lack access to paid family leave. One in four American women experiences intimate partner physical violence, sexual violence, and/or stalking, while one in five American women are sexually assaulted in their lifetime (National Coalition Against Domestic Violence 2020). Across all of these areas, Black and Indigenous women and women of color experience markedly higher levels of poverty, violence, and health disparities, while LGBTQ people face additional forms of discrimination and violence.

For decades, feminists have sought to improve women's status through social protest, cultural transformation, and domestic and international legal reforms. Often called an international bill of rights for women, CEDAW is a binding UN treaty that demands women's full equality in law, the family, politics, economics, education, and society, emphasizes that women must not be confined to stereotypical gender roles, and requires women enjoy control over their reproduction. It defines discrimination against women as "any distinction, exclusion or restriction made on the basis of sex which has the effect or purpose of impairing or nullifying the recognition, enjoyment or exercise by women irrespective of their marital status, on a basis of equality of men and women, of human rights and fundamental freedoms in the political, economic, social, cultural, civil, or any other field" (Article 1). CEDAW furthermore tasks state parties with incorporating women's rights into national legislation, public institutions, and state policy.

President Jimmy Carter signed CEDAW in 1980. While originally garnering bipartisan support, ratification has been stalled by conservative politicians. For example, Republican Senator Jesse Helms, former chairman of the Senate Foreign Relations Committee, argued CEDAW was "clearly negotiated by radical feminists with the intention of enshrining their radical anti-family agenda into international law" (Baldez 2014: p. 175). Anti-CEDAW activists have not only blocked US ratification, but have also attempted to undermine and weaken the treaty's principles in other UN women's rights fora (Sanders 2018; Sanders and Jenkins 2021). Meanwhile, since the 1970s, conservative actors have likewise impeded efforts to pass the Equal Rights Amendment, which would explicitly enshrine sex equality in US constitutional law. In 2010, the Obama administration expressed support for CEDAW and feminists renewed their efforts to promote ratification (Blanchfield 2012: p. 43). However, the treaty has never been put up for a vote on the Senate floor. President Joe Biden and Vice President Kamala Harris have pledged to once again pursue ratification, but the congressional balance of power makes success highly unlikely (Biden Harris 2020).

CEDAW is significant in that it not only prohibits discrimination on the basis of sex, but also mandates affirmative measures to ensure women's equality currently denied to many American women, including provision of healthcare, paid 
maternity leave, and protections for mothers in the workplace. CEDAW also remains important in the USA because treaty principles, such as women's rights to "decide freely and responsibly on the number and spacing of their children and to have access to the information, education and means to enable them to exercise these rights" (Article 16c), are under sustained attack from American opponents of comprehensive sexuality education, contraception, and abortion. The political deadlock over CEDAW is unlikely to change anytime soon. Given this state of affairs, the Cities for CEDAW movement has sought to promote the treaty's principles in local politics. In the following section, we outline how scholars and activists theorize the impact of international legal norms on local policy and practice and how local adoption can, in turn, reverberate outwards.

\section{Conceptualizing Local-Global “Boomerang” Effects}

CEDAW is one of several international treaties that comprise "the legal core of the human rights system" (Merry 2006a: p. 24). Others include the International Covenants on Civil and Political Rights and on Economic, Social and Cultural Rights, the Genocide Convention, the Refugee Convention, the Convention on the Elimination of All Forms of Racial Discrimination (CERD), the Convention against Torture, and the Convention on the Rights of the Child (see UN OHCHR 2021). CEDAW, and to varying degrees the latter three conventions (two of which the USA has ratified, namely the conventions against racial discrimination and torture), are associated with the rise of transnational advocacy networks (TANs) or congeries of nongovernmental organizations (NGOs) that connect across borders. The emergence of a vast array of TANs devoted to human rights of various sorts as well as environmental protection animates what has been called the "boomerang effect" (Keck and Sikkink 1998: p. 12). This occurs when domestic human rights advocates face hostility or indifference to their agendas by their own national governments, and, thus, leapfrog them by organizing at the international level. This can lead to pressure on recalcitrant states to comply with human rights norms. In the case of women's rights advocacy, explicitly feminist movements or transnational feminist networks (TFNs) have joined these efforts, uniting women from the Global North and South to push for change in "local structures, national governments, and global institutions" (Moghadam 2005: p. 20).

More recently, feminist scholars have posited a "double boomerang effect" (Irvine 2013 p. 21) whereby NGOs not only seek international support to pressure national governments, but must also mobilize domestic and regional support to pressure international organizations to observe their own policies and norms. For instance, feminist activists demanded UN personnel live up to their obligations to implement UN Security Council Resolution (UNSCR) 1325 (2000), which calls for women at peacemaking tables, in peacekeeping forces, and in peacebuilding efforts as well as zero tolerance for sexual violence as a weapon of war (Irvine 2013).

These global-local interactions, or glocalizations, reveal the necessity of local mobilizations to produce, disseminate, expand, and enforce international women's rights norms and practices. Building on Keck and Sikkink's (1998) classic 
boomerang effect (through which activists seek international support to pressure national governments) and Irvine's (2013) double boomerang effect (whereby activists additionally seek domestic and regional support to pressure international organizations), we suggest that the Cities for CEDAW model pursues a distinct local boomerang effect. ${ }^{3}$ The local boomerang effect captures activist efforts to horizontally diffuse international human rights norms and practices across localities within nation-states and thus leverage such local support for international human rights to enable or improve national human rights commitment and compliance. Unlike the classic boomerang effect, the local boomerang effect thus relies on an internal, rather than external, lever of influence on states. This dynamic is especially relevant to the USA as one of the very few non-ratifiers of CEDAW, alone among Global North countries. Ironically, a number of international women's human rights TANs (or TFNs) are based in the USA, helping NGOs located elsewhere pressure states that have ratified CEDAW to abide by it, just as many US feminists joined Global South feminists advocating for the realization of the concept of "women's rights are human rights" at the international level to further solidify actions against genderbased (often private realm) rights violations in the decades since CEDAW was put into force (Bunch 1987). Yet, US-based women's rights advocates have no recourse to CEDAW at home.

Facing obstinate conservative opposition to CEDAW ratification in the Senate, feminists in the USA have turned to the Cities for CEDAW initiative as an alternative means of promoting treaty norms. Launched in the mid-1990s, this movement seeks at least one hundred US cities to pass ordinances that obligate them to abide by CEDAW principles (Womack 2015). In doing so, activists emphasize that women's rights are universal and binding, not negotiable policy options (Merry et al. 2010). Instead of relying on Congress to initiate CEDAW compliance, the movement promotes broader cultural shifts toward "equal access to and equity in health care, employment, economic development, and educational opportunities" and against gender-based violence (Lozner 2004: p. 779). This bottom-up approach not only seeks to build translocal support for eventual national CEDAW ratification, but also aims to increase the treaty's weight at the local level, thereby not waiting for some trickle-down effect should ratification ever occur. Local ordinances can also provide greater leverage for activists to impact laws, policies, and practices that most directly affect women's lives on a daily basis.

Cities for CEDAW's urban orientation is also well-placed as American cities are the most progressive and by far the most populous political arenas at present. As Richard Schragger (2008: pp. 44-45) argues, urban populations are often more diverse in terms of age, race, and immigrant status (as well as, we would add, sexual orientation and gender identity) and more highly educated and politically

\footnotetext{
3 Malliga Och (2018: p. 440) suggests briefly that Cities for CEDAW could be viewed as promoting a "reversed boomerang pattern." However, we do not see Cities for CEDAW as reversing the traditional boomerang pattern per se as it still frames its work in relation to an external international treaty to improve national policy. Instead, our concept of a local boomerang effect better captures the campaign's emphasis on an alternative and internal leaver of horizontal diffusion to change conditions, but also hopefully policy, nationally.
} 
progressive than are those in rural and suburban areas. Yet, urban voters are systematically underrepresented in government. Through partisan gerrymandering and voter suppression, many state governments as well as the federal government disproportionately reflect the will of rural and suburban voters, sometimes locking in conservative minority rule (Bronner and Rakich 2021). In this sense, Senate blockage of CEDAW should not be confused with democratic rejection of CEDAW principles, particularly in cities. While progressives have supported a centralization of power invested in the federal government since the New Deal to counter segregationistbased claims for states' rights and overcome many local governments' failure to implement anti-discrimination standards, they are increasingly advocating decentralization of power to enable cities to enact legislation in favor of universal healthcare, a living wage, labor and LGBTQ rights, immigrant sanctuary, and environmental protection (Schragger 2008: pp. 40, 43; Smith 2017). These are all things that the federal government has been unable or unwilling to adequately address. While the federal government needs to constitute a "floor" for rights, cities are laboratories for the considerable, varied, and contagious expansion of them.

Although the local boomerang effect sought by Cities for CEDAW posits that adoption of international human rights conventions at the local level will encourage their institutionalization at the national level, the campaign does not stress CEDAW ratification as its only goal. Indeed, a 2015 report on Cities for CEDAW to the international CEDAW Committee in Geneva during Beijing +20 proceedings noted that while some in the movement are dedicated to US ratification, others see this only as "icing on the cake." As many countries that have ratified CEDAW have not implemented it, the report argued that buy-in by most US cities would constitute a "de facto ratification" with more teeth and impact that could serve as inspiration for women everywhere to locally organize for bottom-up implementation where top-down implementation is not occurring (Cities for CEDAW 2015). Seen in this light, the efficacy of the local boomerang effect depends not just on formal national acceptance of CEDAW, but largely on the extent to which local activism encourages meaningful policy change across the country. Thus, we next consider the implementation of CEDAW at the international level and its relationship to implementation at the local level, followed by an examination of some Cities for CEDAW experiments on the ground.

\section{Arguments for a Local CEDAW Boomerang Effect}

CEDAW, like other UN conventions, carries no enforcement or punishment mechanisms, but has the potential to influence states through a variety of post-ratification processes. States report on their progress with respect to conforming domestic laws and policies to CEDAW principles to the CEDAW Committee of gender equality experts, which, in turn, provides publicly available recommendations to reporting states for improving their compliance. These iterative interactions function as both legitimizing and shaming mechanisms, which can bring about, albeit unevenly and imperfectly, the "cultural production of norms" with respect to gender equality and improve the status of women (Merry 2006a: p. 89). Such norms are constructed as 
universal ones basic to the advancement of women's human rights everywhere and consistent with a culture of "transnational modernity" to which most states aspire to be full members of the international community (Merry 2006a: p. 90). Although the terms of Western-inspired transnational modernity smack of a contemporary civilizing mission (Merry 2006a: p. 73) and are associated with the rise of neoliberal governance through which states are ranked and judged with respect to achieving the trappings of modernity (Merry 2016), they nevertheless create openings for women's human rights activists to have gender equality taken seriously. Moreover, it is frequently marginalized people themselves who have adopted the language of international human rights "in an emancipatory way" and have led "the effort to mobilize around human rights and dignity" (Smith 2017: p. 350).

Despite the success of CEDAW as among the most ratified UN treaties, many states have resisted complying with its requirements. A number of ratifying states have lodged incompatible reservations, have failed to submit an initial report or subsequent ones to the CEDAW Committee, and/or have offered a range of excuses as to why they have not adequately transformed domestic law and practices to conform to CEDAW (De Pauw 2013). The most often cited barriers to compliance, particularly on the part of Global South countries, include lack of resources and/or local patriarchal cultures that cannot be overcome (Merry 2006a: p. 91). The latter claims are problematic on at least two scores: first, they construct all local culture as backward while suggesting that modernity is somehow free of patriarchy; and second, by falling back on cultural explanations, they relieve states from attempting to institute reforms or from taking responsibility for the failures of reform efforts (Merry 2006a: p. 91). Still, there is evidence that those who do report gain constructive recommendations from the CEDAW Committee, which works with state representatives, often ministers of women's affairs and the like, to rethink how to improve gender equality in local contexts (Merry 2006a: p. 91).

At the same time, non-state actors can use CEDAW to pressure ratifying states. Women's human rights NGOs regularly publicize CEDAW Committee recommendations within their own countries if their states fail to do so and produce "shadow reports" on their countries' performance in complying with CEDAW for the CEDAW Committee to consider in making their recommendations. For women within those states that have ratified the Optional Protocol to CEDAW (2000), there is the option for individual women and women's groups to bring violation complaints directly to the CEDAW Committee for adjudication and possible sanctions after exhausting all domestic remedies (Merry 2006a: pp. 78-79).

Domestic NGOs and TFNs also engage in translating CEDAW principles into local contexts, thereby facilitating the diffusion of international norms to empower local women to use these norms as leverage in their struggles to change domestic laws and practices within ratifying states. However, translators can be local and national government officials who may significantly dilute CEDAW principles so as to maintain patriarchal privileges or may fail to "vernacularize" or "indigenize" the principles in such a way that they work better for women (Merry 2006b). Nevertheless, local women may also expand those principles by drawing on CEDAW Committee recommendations which, for example, emphasize eliminating violence against women as necessary to realizing women's human rights (Merry 2006a: p. 
76). They may also take into account more intersectional understandings of women's human rights that recognize the interactions of gender, race, and class or caste discriminations (Zwingel 2005). This is especially relevant to the US context, where intersectional feminism is highly theorized and practiced in movement politics. In these ways, the localization of CEDAW, or "bringing it home," can not only make it an ever-evolving and thus "living" document (Zwingel 2016), but also in some cases a more radical one that goes beyond 1970s imaginings of women's human rights and the culture of transnational modernity that constructs local cultures, perspectives, and practices as the problem, rather than as sources of innovation, particularly when it comes to local women's movements.

To see if the Cities for CEDAW campaign, which is responding to a context in which there is no resort to international women's human rights law or its mechanisms, is nevertheless showing some promise in these directions, we turn to a few established cases and one newer one.

\section{Cities for CEDAW in Practice: Select Cases}

According to Cities for CEDAW, seven US cities and two counties have passed ordinances; 29 cities and counties, and two states have passed resolutions or have them pending; and 31 cities and counties have formed or are forming coalitions to advocate for the passage of resolutions and/or ordinances that endorse local CEDAW compliance (Cities for CEDAW 2019). ${ }^{4}$ The bulk of local jurisdictions with ordinances are in California (San Francisco, Berkeley, Los Angeles, San Jose, and Santa Clara County), but Honolulu, Pittsburgh, Cincinnati, and Miami-Dade County have joined them. Those with resolutions in place and pending as well as those with resolution campaigns in progress are found across the country in many "red" as well as "blue" and "purple" states. They include a range of larger municipalities (such as New York, Philadelphia, Boston, Denver, Phoenix, and Washington DC) and mid-sized and smaller ones (such as Kansas City, Minneapolis, Salt Lake City, New Orleans, Tampa, Louisville, and Eugene).

San Francisco was the first city to pass a CEDAW ordinance in 1998. Advocacy was organized by four local entities - the Women's Institute for Leadership Development for Human Rights, Amnesty International USA Western Region, the Women's Foundation, and the San Francisco Commission on the Status of Women (COSW), which was formed in 1975 and is the stakeholder arm of the Department on the Status of Women (DOSW) established within city government in 1994. This organizing was jumpstarted by the 1995 Fourth World Conference on Women in Beijing and growing recognition of the need to bypass federal resistance to international anti-discrimination norms in the USA (Lozner 2004: pp. 778-779). Key features of the ordinance included the appointment of an eleven-member CEDAW Task Force, which was made up of community organization representatives and elected officials

\footnotetext{
4 As maintenance of the Cities for CEDAW website depends on volunteers, this data may not be fully up-to-date.
} 
and became a permanent seven-member CEDAW Committee in 2002, to monitor progress on the city's observance of CEDAW (and by 2000, CERD) principles and to report this to the COSW and top city governmental officials. The ordinance required the city to address specific challenges: economic development, violence against women, and girls, and healthcare (Hagood Lee 2019: p. 12). It moreover authorized a gender analysis of city government which involved city agencies in human rights training and self-studies to improve the collection of disaggregated data by gender, race, sexual orientation, disability, immigration status, and so on and pro-human rights practices in employment and service provision. It mandated regular reporting of findings and action plans by city agencies to the CEDAW Committee, the COSW, and the public for review and further recommendations (Lozner 2004: pp. 782-785; see also McCreight 2013; Womack 2015).

As observed by Stacy Lozner (2004), the San Francisco ordinance, "like the United Nations human rights regime it is based upon, does not compel city agencies to follow through on their action plans, but, through monitoring and reporting requirements, seeks to 'shape and transform' participants in the problem-solving process" (784). As a form of collaborative governance that continuously engages knowledgeable and committed community stakeholders with local government leaders and agencies, it constitutes a "normative model of compliance" that seeks to advance "norm internalization" through "participatory deliberation, mechanisms of transparency, and capacity building rather than coerced by anticipation of regulation" (Lozner 2004: p. 784). This more collaborative approach that relies on persuasion and capacity building aimed at re-socialization as opposed to superficial and begrudging legal change is particularly effective when it comes to challenging "private wrongs," such as domestic violence against women by non-state actors and increasing state accountability for them (Brysk 2013). In addition, the "participatory approach defused any potential defensiveness or denial about gender inequalities as well as fear of retribution" (Hagood Lee 2019: p. 16). Through these collaborative, constructive, and context-specific deliberations, CEDAW's iterative and transparent reporting and review processes at the international level are somewhat replicated at the local level in the USA (Och 2018: p. 432).

While some programs emerging from San Francisco's existing women's rights institutions such as the COSW and DOSW pre-date the CEDAW ordinance (Hagood Lee 2019: p. 8), the city developed additional initiatives that point to the efficacy of Cities for CEDAW as a tool to further catalyze progressive change. The city improved domestic violence (DV) training for First Responders and Housing Authority staff, reformed police practices, and extended millions in funding through the Violence Against Women Prevention \& Intervention Grants Program to community-based organizations that work with DV survivors, helping the city radically reduce DV-related homicides (Newman and Murase 2015: p. 6). The city also created a Mayor's Task Force on Anti-Human Trafficking. Other examples of progress include efforts by city planners to better integrate accessibility and safety considerations into public infrastructure design; the creation of a girls unit by the Juvenile Probation Department; more gender-inclusive processes to distribute arts grants; and collection of gender-disaggregated data by the Rent Stabilization Board (Hagood Lee 2019: p. 15). San Francisco became the first municipality to offer $100 \%$ paid 
leave to employees who welcomed a new child through birth, adoption, or foster placement (Newman and Murase 2015: p. 7). The city also worked with the private sector to advance the Gender Equality Principles Initiative, which encouraged companies to enact best practices (Hagood Lee 2019: p. 16).

As much as a collaborative approach to compliance bodes well for bringing about deeper social and cultural changes that must occur everywhere to achieve gender equality, the results from the San Francisco case have been mixed. Although the very process of conducting a gender analysis makes institutions under study more gender- and human rights-sensitive (Lozner 2004: p. 783), some of the initial actions taken by individual agencies were relatively minimal. For instance, initiation of flextime and telecommuting, "safe ride" programs, and child-care referrals affected relatively few women and did nothing to question the structural inequalities that make women most responsible for unpaid reproductive labor and most likely to be treated as contingent and irregular workers. Nor did they address barriers to women in all their intersectional diversity (such as by race, sexuality, disability, and so on), focusing instead on unidimensional and essentialist constructions of women as reproducers or potential victims of stranger assault who need to be better accommodated in the workplace (Womack 2015: p. 228).

More encouraging, however, is a 2017 Gender Analysis of San Francisco Boards and Commissions that found a fairly close match between the percentages of women, racial minorities, and sexual minorities on such bodies and the percentages of these groups in the local population (City and County of San Francisco Department on the Status of Women 2017). Still, women of color are underrepresented and the most diverse boards and commissions have the smallest budgets and thus the least decision-making power. More favorable results are mostly a function of the fact that a City Charter Amendment was passed in 2008, which required that membership on boards and commissions be representative of the demographics of the city. Thus, although the DOSW is responsible for tracking progress on this and no doubt the CEDAW ordinance and processes that flowed from it helped to create a climate for such a charter amendment, significant city action appears to occur more in response to codified rules and regulations than to diffuse collaborative processes that the CEDAW ordinance initiated. Indeed, although Los Angeles passed its CEDAW ordinance in 2000, it was the 2015 mayor's Executive Directive requiring all agencies to develop and submit to his office gender equity plans and to appoint gender equity liaisons to the Gender Equity Coalition that appears to be making the most difference in mainstreaming a city-wide gender lens with budgetary implications (Columbia Law School Human Rights Institute 2017: p. 10). This directive accompanied the release of a 2015 gender analysis undertaken by a local university in concert with the city.

Perhaps the most successful result of the San Francisco case has been meeting the goal of becoming a model CEDAW city for the rest of the country (Womack 2015: pp. 217-218). While every city is different and none can or should fully replicate the San Francisco model, the fact remains that San Francisco has produced the most guides for fashioning a local CEDAW initiative, the most data on local gender analysis in the USA, and is the subject of the most literature on this approach. Given that a number of other cities now have ordinances, it is useful to compare experiences, 
particularly with places less resourced than San Francisco or Los Angeles, to assess Cities for CEDAW's efficacy.

In 2015, Cincinnati passed a CEDAW resolution and in 2017, became the seventh US city to adopt CEDAW ordinances, ${ }^{5}$ one of which ordered and funded a gender equity study of City of Cincinnati government. We, the authors, led and participated in the research team that performed the study and wrote the final report, ${ }^{6}$ which was presented to City Council in May 2020 (UC Gender Equity Research Team 2020), while one of us also participated since 2014 in the community-based Cincinnati4CEDAW coalition, formed to advocate for a resolution and then ordinances. ${ }^{7}$

The other Cincinnati CEDAW-inspired ordinance, similar to the San Francisco one, authorized the creation of a Gender Equality Task Force with a minimum of seven members representing the community and elected officials. That Task Force was appointed by the mayor in Fall 2017 and included fourteen members from local women's, labor, human rights, social service, religious, and education organizations (including a few Cincinnati4CEDAW coalition representatives) as well as two city employees, a City Council member, and a state representative-all women, including some women of color. The coalition had some input into the mayor's choices, but representation was ultimately based more on sectoral than intersectional identity categories. This Task Force served in an advisory and reporting capacity and was responsible for relaying the results of the gender equity study, and making recommendations arising from it for further study and improvements. While the Task Force's initial mandate expired, its life has so far been extended to actualize the recommendations of the gender study, including the creation of a more permanent body in the form of a sufficiently staffed gender equity commission, which could track and make further recommendations for policy and legislative changes.

The minimal funding provided by Cincinnati for its gender study ${ }^{8}$ and the absence, thus far, of a permanent infrastructure, funding stream, and accountability scheme for overseeing and implementing further study, review, and recommendations are

\footnotetext{
5 The nine-member, Democratic-majority Cincinnati City Council unanimously passed these ordinances. The fact that similar-sized Midwest cities had adopted either a resolution (Louisville) or an ordinance (Pittsburgh), effective lobbying by local women's organizations, and funding pledges for the proposed gender study from coalition organizations and University of Cincinnati sources all facilitated passage. Contrary to the claim made by Och (2018: p. 438), the Cincinnati ordinances authorizing a gender study and task force do invoke CEDAW as a source of inspiration for them (just as the prior resolution referred to CEDAW). Like most other local ordinances, CEDAW appears more as what Och (2018) calls a "framing" device rather than a "grafting" one in which actual CEDAW language is used to fashion local law.

6 The study, Gender Equality Analysis of the Municipal Government of the City of Cincinnati, was reviewed by the the Institutional Review Board at the University of Cincinnati, Study ID: 2017-3977.

7 This coalition emerged out of class project assigned in a city planning course offered by feminist sociologist Jan Fritz in the School of Planning at the University of Cincinnati. Fritz (2018) has recently written about the optimal organizing strategies for local Cities for CEDAW campaigns and the value of keeping close connections with the national initiative and the Commission on the Status of Women in the UN to which it is linked, given how women's experiences at UN conferences and gatherings provided the impetus and ongoing support for local activism.

8 Cincinnati contributed $\$ 8000$ toward its gender study, with additional funds procured from local NGOs and the University of Cincinnati, compared to $\$ 100,000$ in city funding for San Francisco's CEDAW Task Force in just its first year (Hagood Lee 2019, p. 12).
} 
what most separate the Cincinnati experiment from the San Francisco or Los Angeles ones at this juncture. Arguably, these factors have tempered the impact of Cities for CEDAW in the city.

Prior to the CEDAW ordinances, Cincinnati had a mixed history of attending to equity concerns in general and gender equity specifically. Reflecting its large Black population, location on the Ohio River just north of the Mason-Dixon line, and long history of both abolitionism and racial tension, ${ }^{9}$ Cincinnati has traditionally seen its inequality problem as primarily race-based. It had a history of legally discriminating against LGBTQ people until voters did away with discriminatory legislation in 2004 , followed by the passage of an amendment to the city's human rights ordinance that extended rights and protections to LBGTQ people in 2006. The city's anti-discrimination policy in Sect. 914 of the Municipal Code now bars discrimination on the basis of "race, gender, age, color, religion, disability status, marital status, sexual orientation, or transgender status, or ethnic, national or Appalachian regional origin" (see City of Cincinnati 2021). Cincinnati is also the home of the plaintiff who launched Obergefell v. Hodges (2015), the US Supreme Court case that nationally legalized same-sex marriage and was the first US city to ban gay conversion therapy that same year (Coolidge 2015). The city more recently adopted an immigrant-welcoming public campaign and declared itself a sanctuary city in 2017.

Different from San Francisco (and other similar cities, such as Los Angeles), there is no Cincinnati Commission (or Department) on the Status of Women, although at the regional level, the Hamilton County Commission on the Status of Women and Girls was formed in 2017. Appointments to that thirty-member group were finalized at about the same time as the city Gender Equality Task Force, and the two groups engaged in fruitful communication. Prior to these developments, studies of the status of women in the region, initially not affiliated with the Cities for CEDAW initiative, were performed by the Women's Fund of the Greater Cincinnati Foundation. In addition, the city performed its own internal gender salary equity study at the supervisory level in 2015, which found that seniority as opposed to gender accounted for most salary inequities although with no analysis of how these might be intertwined. It also began to provide paid parental leave to its employees in 2015, consistent with the adoption of similar policies by other area public sector employers and major transnational corporations headquartered in Cincinnati.

The CEDAW-inspired gender equity study of Cincinnati included a dual focus on the city's internal human resources policies and practices and external public-facing service provision. Rather than conducting human rights training and self-study facilitation at the outset, our research team (consisting of faculty largely from Political Science and Women's, Gender, and Sexuality Studies with quantitative and qualitative expertise) engaged in a more data-driven approach. This strategy is consistent with what Sally Engle Merry et al. (2010) found in their study of a New York City Human Rights Initiative, designed to produce a law that would include observance of CEDAW and CERD in city government. Much social movement activism

\footnotetext{
9 These dynamics resulted in a federally mandated and now model police-community collaborative agreement after the police killing of an unarmed Black teenager in 2001.
} 
and NGO energy was originally directed at expanding community engagement and accountability to the community through the prospective law, but ultimately the effort to get it passed portrayed the measure as a matter of "good governance." This meant focusing on data-driven audits to be performed by city agencies to determine their performance with respect to gender and race equity.

Our 2-year (2017-2019) gender equity analysis thus included a quantitative analysis of personnel and budget data provided by Human Resources and the city's budget director to establish a "rough cut" of the gender and race wage gap among employees across and within departments of varying sizes and budgets, supplemented by the study of women appointed to boards and commissions recently completed by the Women's Fund. This was followed by "deep dive" case studies of five departments via an online survey to establish employee perceptions of their workplace environment. ${ }^{10}$ This deeper investigation of four of those departments also included a gender-responsive budget analysis, textual analysis of relevant department documents (such as mission statements, strategic plans, program and job descriptions, policy manuals, and collective bargaining agreements) to determine gender bias or sensitivity and select interviews and focus groups conducted after the survey to gain more insight and encourage improvement in gender (and race and sexuality) equity practices.

We strategically selected the five case study departments on the basis of examples of the most female-heavy (health), most gender-balanced (economic and community development and city planning), and most male-heavy departments (fire and secondarily police, together accounting for $66 \%$ of the city's operational budget) that are related to such gender issues as women's health (including reproductive health), economic opportunity, and bodily safety. Our data analysis found that across all city departments in aggregate and on average from 2013 to 2017, women made $\$ 2.83$ per hour less than men and non-whites (almost entirely African Americans) made $\$ 4.10$ less than whites. However, when adjusted for such factors as education, job title, and other relevant controls, these gaps lessened significantly within job categories (a \$0.09 per hour differential for women and a $\$ 0.13$ per hour differential for non-whites), which are largely regulated by union contracts and civil service rules. Still there is evidence that women and Black people tend to be least represented in higher-paying jobs. Moreover, findings from the online survey conducted in Summer 2018 suggest that the greatest dissatisfaction with employment and promotion conditions is felt most by women in a few departments (primarily fire and health) and people of color across all of them. Data from the Women's Fund's study of the city's sixty boards and commissions that we drew upon also show that women are highly underrepresented on them. The Women's Fund postulates, in the absence of race data, that women of color are least represented (just as women of color in the

\footnotetext{
10 All employees of targeted departments were surveyed, with the following response rates. Police: 490 responses $(37.8 \%)$ of which $71 \%$ were white and $35 \%$ were females; fire: 333 responses $(35.7 \%)$ of which $77 \%$ were white and $11 \%$ were females; health: 212 responses $(40.3 \%)$ of which $56 \%$ were white and $90 \%$ were females; development: 43 responses $(55.8 \%$ ) of which $56 \%$ were white and $52 \%$ were females; city planning: 10 responses $(83.3 \%)$ of which $86 \%$ were white and $71 \%$ were females.
} 
city predominate among the poor and are most at risk from other structural inequalities). A voluntary survey of one hundred appointed board and commission members conducted by the City of Cincinnati (2018) found that over two-thirds identified as white and/or male, earned exceptionally high incomes, and lived in the city's wealthiest neighborhoods, including suburbs outside of municipal borders. These initial findings, which were presented by our research team and the City Task Force in a preliminary report to City Council and members of the public in 2018, helped underscore a new city requirement that future appointments seek representation more proportional to city demographics. Hamilton County committed by resolution to achieve the same goal in 2018 . The city and county have also implemented policies that bar asking applicants for past salary information to avoid low-balling offers to women and racial minority prospects as a result of recommendations made by the City Task Force in concert with our research team and County Commission.

Our departmental case studies revealed further significant information. For example, our analysis of the Cincinnati Police Department (CPD), which consumes $36 \%$ of the City's budget, found that sworn officers are mostly white males at levels highly disproportionate to the public served and that relative to their numbers within the department, white males are overrepresented in many promotional ranks. Moreover, workplace diversity has not markedly improved since the 1980s. Despite their objective predominance within the department, white male survey respondents frequently perceived that they are victims of "reverse discrimination," especially via CPD's longstanding Consent Decree concluded after past allegations of racism and sexism, which requires affirmative efforts to hire and promote qualified women and racial minorities. Some CPD survey respondents made disparaging comments about women and racial minorities. The latter, who are objectively underrepresented, not surprisingly also expressed perceptions of discrimination and disrespect. Our report therefore recommended substantive efforts to address inaccurate perceptions that white males are excluded from hiring or promotion within the department and endorsed further efforts to hire more diverse officers, among other suggestions.

In terms of public-facing policy, our study focused on policing gender-based violence, specifically domestic violence (DV). In interviewing officers, the city prosecutor, and experts, we found that DV training is inconsistent and that officers may not always follow extant procedures. ${ }^{11} \mathrm{We}$ also noted Cincinnati's poor DV conviction rate, fueled in part by the challenge of securing victim court testimony. On the positive side, we found evidence for the benefits of Cincinnati's innovative Domestic Violence Enhanced Response Team (DVERT) program, which dispatches trained victim advocates from the social service agency Women Helping Women to assist DV survivors at all DV calls for police service in the city. Based on these findings, our report made numerous recommendations, including more DV training to improve officer interactions with survivors, expanding the DVERT program,

\footnotetext{
11 Twelve informants including police officers, the city prosecutor, and DV experts at the survivor social service agency Women Helping Women were interviewed over the course of our research on the policing.
} 
instituting evidence-based prosecution for DV offenses (which is less reliant on survivor testimony), and expanding preventative DV education programs.

There is some evidence that our recommendations have been impactful. Highranking CPD officers attended the presentation of the final report to City Council and pledged to act on its findings, particularly with respect to evidence-based prosecution. The COVID-19 pandemic has led to an alarming spike in domestic violence and homicides (McGee 2020), creating great urgency to improve police response. Consequently, City Council invested $\$ 250,000$ in the otherwise grant-funded DVERT program in fall 2020 (McGee 2020), extending funding in the city's subsequent budget. Yet, overall progress is likely to be halting and slow as police departments facing scrutiny on numerous fronts often take a defensive posture toward criticism, especially in face of the Black Lives Matter movement's demands for substantial police reform (Cooper 2020). Without specific accountability mechanisms and a permanent gender equity commission to monitor progress, change depends on the good will of local leaders. Nonetheless, our study puts on the record objective information that can and should be used by city officials to enhance gender as well as race and other forms of equity in the future.

On the other end of the gender and budgetary spectrum from the Police Department, the female-heavy Health Department, constituting a mere 5\% of the City budget and largely dependent on state funding and federal grants (thus underscoring local public health insufficiencies laid bare by the pandemic), was found to serve primarily low-income women of color, but almost exclusively as mothers. Ironically, female Health Department workers, the majority of whom are women of color (specifically African American) in lower-end service provision jobs, reported in our survey that their roles as caretakers at home negatively influenced their sense of respect and happiness on the job. While a number of programs focused on maternal and infant health were found to be laudable and in line with ameliorating maternal and infant mortality rates above the national average in Cincinnati where poverty and income inequality, particularly by race, are also well above the national average, the focus on women almost entirely as mothers has led to a still minimal focus on men's reproductive health and responsibilities as well as inattention to women's health across the life cycle (particularly post-reproductive years) and to the health of those identifying as LGBTQIA. Indeed, only recently have intake forms allowed for clients to identify themselves in terms of diverse sexualities and genders, but such identifications remain heavily underreported in part due to a heterosexual and cis gender-normative bias in the department as reflected in textual material and reported by focus group respondents who consisted of directors of gender-oriented programs, such as reproductive, maternal, and men's health.

The federally funded Reproductive Health and Wellness Program is the most innovative and progressive in the department and most reflective of CEDAW principles in its efforts to empower diverse women to make reproductive choices and insist upon sexual consent. Also, innovative and potentially game-changing is the department's Health in All Policies (HiAP) initiative as part of a Centers for Disease Control and Prevention Strategy to make health and well-being a priority by national to local-level governments. It is meant to integrate physical, mental, and emotional health as well as health equity into all policy undertakings in Cincinnati, 
including construction, housing, transportation, and education, and is addressed in the Health Department's 2016-2021 Strategic Plan. The five key elements of the HiAP framework through which health should be mainstreamed across City undertakings include promoting health, equity, and sustainability; supporting intersectional collaboration; benefitting multiple partners; engaging stakeholders; and creating structural or procedural change. However, according to focus group respondents, while the HiAP Committee has given some attention to the race and class make-up of neighborhoods in which health might be compromised by City policies, there is no real attention to gender effects. While the pandemic further obviates the need for health equity mainstreaming, it also produces crisis management and stretched services, militating against deliberative action.

Moreover, given that such departments as Planning and Community and Economic Development, which our research team also studied in-depth, constitute less than $1 \%$ of the City budget each and thus are highly strapped, it is unlikely that such health equity mainstreaming can be adequately conducted. While these genderbalanced departments, albeit with relatively few employees, showed an overall commitment to equity and inclusion and had some specific programs that supported outreach to racial minority neighborhoods and women- and minority-owned businesses, they lack either formal procedures for determining how well they engage women and racial minorities, and particularly women of color, or attention to the needs of women (and men) in all their diversity, with immigrant and trans women as well as sexual minorities in particular falling through the cracks. At the time of our study, many social services supported by federal dollars were outsourced by the Community and Economic Development Department to the United Way for distribution, thus also diminishing City oversight and accountability for how adequately such funding is used to support gender and intersectional equity and inclusion. While our analysis and recommendations for these departments, as well as the Health Department, were received well by already fairly enlightened and well-intentioned leadership, the challenge of sufficient resources and training remains. In the absence so far of a permanent and staffed gender equity commission to monitor progress and until equity and inclusion become an overarching strategic goal of the City, the question of implementation looms even larger.

Nevertheless, we hope that this kind of policy analysis will be just the beginning of a long-term process to bring about greater gender, race, and other equities in the local area, particularly as the pandemic recedes and more support for local and state governments is forthcoming from Congress and the Biden administration and given that the Gender Equality Task Force leaders continue to lobby City Council members to take up more of the report's recommendations. But as we have suggested, this will require not just time, but permanent infrastructures, funding, and some form of regulatory accountability to work best at the local level. While the Cincinnati case indicates that the Cities for CEDAW model is being adopted throughout the heartland, thereby further legitimating the principles of CEDAW and inculcating the norms and practices associated with their realization, we argue in our final section that this horizontal diffusion (albeit one still limited and nowhere close to 100 cities)—which aspires to catalyze a local boomerang effect—may not result in an upswell of support, and is no substitute for national ratification of the convention. 


\section{The Local Boomerang Effect: Opportunities and Obstacles}

What does the Cities for CEDAW campaign and its efforts in places such as San Francisco and Cincinnati tell us about the capacity of grassroots advocacy to realize international women's rights law through local governance? We argue that the movement points to promising possibilities for this model of activism in terms of its horizontal impact, largely within the USA, but see obstacles along the way as well as limited hope for its vertical impact on US national policy via the local boomerang effect.

As we have outlined in the preceding discussion, the most significant aspect of the Cities for CEDAW approach is its capacity to promote women's rights principles on the ground, thus preempting a common failing of international agreements, which struggle to translate states' legal commitments into meaningful compliance (Merry 2006b; Risse, Ropp, and Sikkink 2013). While there is an ongoing debate over the precise effects of treaty ratification on state behavior, there is often a significant gap between rhetoric and practice (Simmons 2009). By coupling CEDAW endorsement with the immediate pursuit of a range of specific and concrete actions such as data gathering, policy review, gender-sensitive budgeting, and policy reform, the Cities for CEDAW model encourages local governments to recognize patterns of gendered discrimination and exclusion and pursue necessary work to advance gender and intersectional equity. Moreover, the practical interactions among policymakers and CEDAW activists that occur through these processes contribute to the vitality of CEDAW norms themselves, which are given life and meaning through practical enactment and social grounding (Brunnée and Toope 2010; Krook and True 2010). By insisting on the pursuit of greater gender justice not just as a matter of good policy, but also as a matter of legal obligation in the immediate form of local ordinances and the more distant form of treaty compliance, Cities for CEDAW reinforces the legitimacy and compliance pull of CEDAW standards.

As the Cities for CEDAW model advances, and if it can sustain its momentum, it also provides a template and toolkit for communities across the country that are seeking new ways to advance women's rights. Activists can easily borrow and adapt best practices from other cities. It is significant that the campaign has gained traction in locales such as Cincinnati, Pittsburgh, Louisville, and Salt Lake City, not just traditionally leftwing coastal metropolises such as San Francisco and Los Angeles. As we have pointed out, because urban municipalities are often more open to progressive politics, including feminist advocacy, than surrounding regions in conservative parts of the country, local activism can provide a vehicle for forms of human rights norm adoption and implementation that are politically blocked at higher levels of government. The degree to which local jurisdictions in the USA incorporate the spirit or letter of CEDAW, they "challenge the usual assumption that local governments are largely subordinate to their states, limited to providing basic services, and unable to play a real policy-making role" (Resnik 2008: p. 83).

Improving gender equity in local government policy and practice is a significant end in itself. Raising awareness and formally placing gender on the agenda of 
policymakers who may otherwise ignore such concerns are making a difference, albeit unevenly depending on the municipality, its resources, and the length of time CEDAW ordinances have been in place and sustained by leaders and advocates inside and outside local government. Indeed, our cases point to the necessity for more permanent rules, regulation, infrastructure, and funding arising from local mobilization and collaborative consciousness-raising and capacity building. Due to its hospitable political culture and greater resources, San Francisco, in particular, may remain a unique case in this regard. While Cities for CEDAW has made inroads into traditionally conservative regions of the country and we provide evidence of some policy impacts that a data-driven gender study in the context of a Cities for CEDAW initiative can have even initially, there is every reason to anticipate that local compliance with CEDAW principles informed by more intersectional approaches may not enhance women's rights beyond the borders of already more progressive municipalities and counties, which may falter in their commitments under the pressures of crisis management and dwindling local resources. Therefore, even when local activism is successful, only those in strong rights-protecting jurisdictions and those with the wherewithal to relocate to them can lay claim to the minimum rights that CEDAW articulates. In addition to potentially uneven adoption of CEDAW principles, many of the policies necessary to advance women's rights such as better provision of healthcare are often too expensive and complex to be realized at the local level. Moreover, despite growing numbers of resolutions and ordinances and a 2014 US National Conference of mayor's resolution in support of CEDAW, on the whole, there is little public awareness of CEDAW, no consistent approach to gathering baseline data, and a plethora of unevenly empowered and conflicting jurisdictions that may or may not be friendly to this approach in the USA (Cities for CEDAW 2015).

It is furthermore important to note that "glocal" policy reform is not only limited by state and national jurisdictions in the USA, but also not necessarily scalable to countries that lack diffused centers of power. While grassroots human rights activism plays a critical role in improving national policy in all countries in the world, local jurisdictions do not always hold the relative independence and influence that they do in the USA's federal system. In other words, American municipalities and counties can have a potentially significant impact on women's rights because they control numerous programs that impact women's status, have relatively large budgets, and make important decisions that affect gender equity. Local communities that lack the political opportunity structure afforded by these resources and capacities are less likely to be able to realize CEDAW or other related treaty requirements, even if they want to.

Finally, from a global political perspective, de facto ratification arising from 100 US jurisdictions adopting and implementing (albeit so far non-standard) CEDAW ordinances is not a substitute for de jure ratification at the national level. By ratifying treaties, states contribute to global consensus that treaty norms are appropriate and obligatory. Even if they fail to fully comply with treaty provisions, ratification communicates a message to the international community. When one of the most powerful and influential states in the world refuses to formally ratify, it weakens the treaty's influence and thus the capacity of activists to leverage treaty provisions to 
demand real change. Even more significantly, American foreign policy has actively interfered with other countries' capacity to fulfill CEDAW requirements. For example, the Trump administration's extreme version of the Mexico City Policy, also known as the "global gag rule," withdrew all US foreign aid funding for NGOs that provide abortion services with their own funds or inform women about abortion (Filipovic 2017). Although this policy has been rescinded by the Biden administration, it has done long-lasting harm to the ability of poor women in the Global South to access not just abortion, but all forms of healthcare provided by NGOs (Sharma et al. 2021). These dynamics are echoed within the USA as conservative politicians strip federal funds from healthcare providers such as Planned Parenthood. The Biden administration has also lifted this "domestic gag rule" (Ollstein 2021), but such policies can be reinstituted under executive orders by future administrations. Further exacerbating this situation is the now very real potential that Roe v. Wade (1973) could be overturned or made practically meaningless by a majority conservative Supreme Court.

Ultimately, some initiatives to address women's inequality must be adopted at the national level to be effective. Current federal law and policy lack a floor for women's rights, which CEDAW ideally provides. Instead, a patchwork of wildly different (copious vs. few) women's rights protections exist within and across states. Accordingly, the USA desperately needs a national health policy that extends quality, accessible healthcare, including reproductive healthcare, to poor women, particularly racialized women, a national family leave policy, and national domestic violence initiatives, including gun control. Otherwise, there is risk of highly uneven norm adoption and implementation. While formal CEDAW ratification would not automatically translate into national policy change, it would allow feminist activists to leverage US commitments to press for greater progress (Simmons 2009). These circumstances obviate another role for local activists - the necessity to vote in federal legislators, perhaps arising from legislative experience in CEDAW cities, who will ratify the convention.

\section{References}

American Association of University Women (2021) The gender pay gap. https://www.aauw.org/issues/ equity/pay-gap/. Accessed 10 Jul 2021

Baldez L (2014) Defying convention: US resistance to the UN treaty on women's rights. Cambridge, Cambridge University Press

Baldez L, Epstein L, Martin AD (2006) Does the U.S. constitution need an Equal Rights Amendment? Journal of Legal Studies 35, 243-283

Biden Harris (2020) Fact sheet. https://joebiden.com/fact-sheet-international-womens-day/\#. Accessed 10 Jul 2021

Bunch C (1987) Passionate politics: Feminist theory in action. New York: St. Martin's Press

Blanchfield L (2012) The U.N. Convention on the Elimination of All Forms of Discrimination against Women (CEDAW): Issues in the United States ratification debate. Journal of Current Issues in Globalization 5(1), 39-64

Bronner L, Rakich N (2021) Advantage, GOP. FiveThirtyEight, https://fivethirtyeight.com/features/advan tage-gop/. Accessed 10 Jul 2021 
Brunnée J, Toope ST (2010) Legitimacy and legality in international law: An interactional account. Cambridge, Cambridge University Press

Brysk A (2013) Changing hearts and minds: Sexual politics and human rights. In Risse T, Ropp SC, Sikkink K (eds) The persistent power of human rights: From commitment to compliance. Cambridge, Cambridge University Press, 259-274.

Cities for CEDAW (2015) Report to the CEDAW Committee. http://citiesforcedaw.org/wp-content/uploa ds/2020/03/Report-by-the-United-Nations-NGO-Committee-on-the-Status-of-Women-New-York. pdf. Accessed 10 Jul 2021

Cities for CEDAW (2017) Cities for CEDAW: A campaign to make the global local. http://citiesforcedaw. org/wp-content/uploads/2020/03/CEDAW-toolkit-July-2017.pdf. Accessed 10 Jul 2021

Cities for CEDAW (2018) Resources. http://citiesforcedaw.org/resources/. Accessed $10 \mathrm{Jul} 2021$

Cities for CEDAW (2019) Status of local activities. http://citiesforcedaw.org/wp-content/uploads/2020/ 03/Landscape-Citiesfor-CEDAW-Branded-for-Website-June-27-2019.pdf. Accessed 10 Jul 2021

City and County of San Francisco Department on the Status of Women (2017) Gender analysis of San Francisco commissions and boards. http://citiesforcedaw.org/wp-content/uploads/2020/03/ SFDOSW-Gender-Analysis-of-Commissions-and-Boards-2017-FINAL-1.pdf. Accessed 10 Jul 2021

City of Cincinnati (2018) Survey of volunteers on Cincinnati boards and commissions. http://city-egov. cincinnatioh.gov/Webtop/ws/council/public/child/Blob/49701.pdf;jsessionid=C37AEE2953CAC81 1DDB14F607448AEF5?rpp=-10\&m=2\&w=doc_no\%3D\%27201800302\%27. Accessed 1 Feb 2019

City of Cincinnati (2021) Equity in Cincinnati. https://www.cincinnati-oh.gov/cityofcincinnati/equity-incincinnati/. Accessed 10 Jul 2021

Columbia Law School Human Rights Institute (2017) Gender equity through human rights: Local efforts to advance the status of women and girls in the United States. http://www.law.columbia.edu/sites/ default/files/microsites/human-rights-institute/gender_equity_through_human_rights.pdf. Accessed 10 Jul 2021

Coolidge S (2015) Council votes to ban gay 'conversion' therapy in Cincinnati. Cincinnati Enquirer, https://www.cincinnati.com/story/news/politics/2015/12/09/7-2-vote-imposes-ban-conve rsion-therapy-cincinnati/76993924/. Accessed 10 Jul 2021

Cooper F (2020) Cop fragility and blue lives matter. University of Illinois Law Review, 2020(2),621-662

De Pauw M (2013) Women's rights: From bad to worse? Assessing the evolution of incompatible reservations to the CEDAW convention. Utrecht Journal of International and European Law 29(77), 51-65

Escobar A (2001) Culture sits in places: Reflections on globalism and subaltern strategies of localization. Political Geography 20, 139-174

Filipovic J (2017) The global gag rule: American's deadly export. Foreign Policy, March/April. http:// foreignpolicy.com/2017/03/20/the-global-gag-rule-americas-deadly-export-trump-africa-womenreproductive-rights/. Accessed $10 \mathrm{Jul} 2021$

Fritz J (2018) Cities for CEDAW: Notes on the road to effective intervention. In Saccà F (ed) Democracy, power and territories. Milano: Franco Angeli

Hagood Lee S (2019) Thinking globally, acting locally: CEDAW and women's human rights in San Francisco. Societies Without Borders 13(1), https://scholarlycommons.law.case.edu/swb/vol13/ iss $1 / 6$. Accessed $10 \mathrm{Jul} 2021$

Irvine JA (2013) Leveraging change. International Feminist Journal of Politics 15(1), 20-38

Keck ME, Sikkink K (1998) activists beyond borders: Advocacy networks in international politics. Ithaca, NY: Cornell University Press

Kemmis S, McTaggart R, Nixon R (2014) The action research planner: Doing critical participatory action research. Singapore: Springer

Krook ML, True J (2010) Rethinking the life cycles of international norms: The United Nations and the global promotion of gender equality. European Journal of International Relations 18(1), 103-127

Lindell I (2009) 'Glocal' movements: Place struggles and transnational organizing by informal workers. Geografiska Annaler. Series B, Human Geography 91(2), 123-136

Lozner SL (2004) Diffusion of local regulatory innovations: The San Francisco CEDAW ordinance and the New York City Human Rights Initiative. Columbia Law Review 104(3), 768-800

Martin N, Montagne R (2017) Nothing protects black women from dying in pregnancy and childbirth. ProPublica, https://www.propublica.org/article/nothing-protects-black-women-from-dying-in-pregn ancy-and-childbirth. Accessed 10 Jul 2021 
Merry SE (2006a) Human rights \& gender violence: Translating international law into local justice. Chicago: University of Chicago Press

Merry SE (2006b) Transnational human rights and local activism: Mapping the middle. American Anthropologist 108(1), 38-51

Merry SE (2016) The Seductions of quantification: Measuring human rights, gender violence, and sex trafficking. Chicago: University of Chicago Press

Merry SE, Levitt P, Rerban Rosen M, Yoon DH (2010) Law from below: Women's human rights and social movements in New York City. Law \& Society Review 44(1), 101-128

McCreight QC (2013) A realization of 'thinking globally' and 'acting locally': A new framework for incorporating international treaties in the United States. MA Thesis in Global and International Affairs, University of California, Santa Barbara

McGee J (2000) Local agency: Domestic violence cases on the rise during COVID-19 pandemic. WLWT, https://www.wlwt.com/article/local-agency-domestic-violence-cases-on-the-rise-during-covid-19pandemic/34279002\#. Accessed 10 Jul 2021

Moghadam VM (2005) Globalizing women: Transnational feminist networks. Baltimore, MD: The Johns Hopkins University Press

Newman E, Murase EM (2015) Local implementation of CEDAW and Cities for CEDAW campaign leadership: report to UN CEDAW Committee. San Francisco Department on the Status of Women. https://sfgov.org/dosw/sites/default/files/UN\%20CEDAW\%20Report_San\%20Francisco\% 20DOSW_101615\%20FINAL.pdf. Accessed 10 Jul 2021

National Coalition Against Domestic Violence (2020) Domestic violence. https://assets.speakcdn.com/ assets/2497/domestic_violence-2020080709350855.pdf?1596828650457. Accessed 10 Jul 2021

Och M (2018) The local diffusion of international human rights norms - understanding the Cities for CEDAW campaign. International Feminist Journal of Politics 20(3), 425-443

Obergefell v. Hodges, 576 U.S. 644 (2015)

Ollstein AM (2021) Biden rolls back Trump's anti-abortion curbs on family planning funds. Politico, https://www.politico.com/news/2021/04/14/biden-trump-anti-abortion-family-planning481395. Accessed 10 Jul 2021

Risse T, Ropp SC, Sikkink K, eds (2013) The persistent power of human rights: From commitment to compliance. Cambridge, Cambridge University Press

Resnik J (2008) New federalism(s): Translocal organizations of government actors (TOGAs) reshaping boundaries, policies, and laws. In why the local matters: Federalism, localism, and public interest advocacy, Papers from the Eleventh Annual Liman Colloquium at Yale Law School, 83-99. https:// law.yale.edu/sites/default/files/documents/pdf/liman_whyTheLocalMatters.pdf. Accessed $10 \mathrm{Jul}$ 2021

Roudometof V (2015) The glocal and global studies. Globalizations 12(5), 774-787

Sanders R, Jenkins LD (2021) Pushback against sexual and reproductive health and rights in the USA. In Power over rights: Understanding and countering the transnational anti-gender movement, Volume II, The Centre for Feminist Foreign Policy, https://static1.squarespace.com/static/57cd7cd9d482e97 84e4ccc34/t/60cb90dc89619a5c8234aadf/1623953630210/PowerOverRights2_web.pd. Accessed 10 Jul 2021

Sanders R (2018) Norm Spoiling: Undermining the International Women's Rights Agenda. International Affairs 94(2), 271-291

Schragger RC (2008) The progressive city. In why the local matters: federalism, localism, and public interest advocacy, papers from the Eleventh Annual Liman Colloquium at Yale Law School, 39-50. https://law.yale.edu/sites/default/files/documents/pdf/liman_whyTheLocalMatters.pdf. Accessed 10 Jul 2021

Simmons BA (2009) Mobilizing for human rights: International law in domestic politics. New York, Cambridge University Press

Smith J (2017) Local responses to right-wing populism: Building human rights cities. Studies in Social Justice 11(2), 347-368

Sharma B, Maclean R, Lopez O, Gladstone R (2021) Health providers worldwide welcome Biden reversal of anti-abortion rule. The New York Times, https://www.nytimes.com/2021/01/29/world/asia/ gag-rule-abortion.html. Accessed 10 Jul 2021

UN General Assembly, Convention on the Elimination of All Forms of Discrimination Against Women, 18 December 1979, United Nations, Treaty Series vol. 1249, p. 13

UC Gender Equity Research Team (2020) Gender study of City of Cincinnati government: Final report for phase one (2017-2018) and two (2018-2019). tinyurl.com/16iul8vo 
UN OHCHR (United Nations Office of the High Commissioner for Human Rights) (2021) The core international human rights instruments and their monitoring bodies, https:/www.ohchr.org/en/profession alinterest/pages/coreinstruments.aspx. Accessed 10 Jul 2021

Womack ML (2015) The intricacies of adopting international 'norms' from the bottom up. Wagadu 13, 211-233

Zwingel S (2005) From intergovernmental negotiations to (sub)national change. International Feminist Journal of Politics 7(3), 400-424

Zwingel S (2016) Translating women's rights: The CEDAW convention in context. London, Palgrave Macmillan

Publisher's Note Springer Nature remains neutral with regard to jurisdictional claims in published maps and institutional affiliations. 